\title{
6 OPEN ACCESS \\ Sleep patterns in children with autistic spectrum disorders: a prospective cohort study
}

\author{
Joanna S Humphreys, ${ }^{1}$ Paul Gringras, ${ }^{2}$ Peter S Blair, ${ }^{3}$ Nicola Scott, ${ }^{4}$ John Henderson, ${ }^{3}$ \\ Peter J Fleming, ${ }^{3}$ Alan M Emond ${ }^{3}$
}

${ }^{1}$ Hospital for Sick Children, Toronto, Canada

${ }^{2}$ Guy's and St. Thomas' NHS

Foundation Trust, London, UK

${ }^{3}$ Centre for Child and

Adolescent Health, University

of Bristol, School of Social \&

Community Medicine, Bristol

UK

${ }^{4}$ Department of Psychology,

Crosshouse Hospital,

Kilmarnock, Ayrshire, UK

\section{Correspondence to}

Professor Alan Emond, Centre for Child and Adolescent Health, School of Social and Community Medicine, University of Bristol, Oakfield House, Oakfield Grove, Bristol BS8 2BN, UK; alan.emond@bristol.ac.uk

Received 19 March 2013 Revised 16 July 2013 Accepted 31 July 2013 Published Online First 23 September 2013

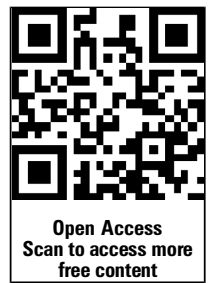

\section{SLinked}

- http://dx.doi.org/10.1136 archdischild-2013-304150

To cite: Humphreys JS, Gringras P, Blair PS, et al. Arch Dis Child

2014;99:114-118.

\section{ABSTRACT}

Objective To investigate longitudinal sleep patterns in children with autistic spectrum disorders (ASDs).

Study design Prospective longitudinal study using Avon Longitudinal Study of Parents and Children, an English cohort born in 1991-1992. Parental reports of sleep duration were collected by questionnaires at 8 time points from 6 months to 11 years. Children with an ASD diagnosis at age 11 years $(n=73)$ were identified from health and education records.

Results From aged 30 months to 11 years old, children with ASD slept for 17-43 min less each day than contemporary controls. No significant difference in total sleep duration was found in infancy, but from 30 months of age children with ASD slept less than their peers, a difference that remained significant after adjusting for sex, ethnicity, high parity and epilepsy. The reduction in total sleep was wholly due to changes in night rather than daytime sleep duration. Night-time sleep duration was shortened by later bedtimes and earlier waking times. Frequent waking ( 3 or more times a night) was also evident among the children with ASD from 30 months of age. Age-specific decreases of >1SD within individuals in sleep duration across adjacent time points was a predictor of ASD between 18 months and 30 months of age $(p=0.04)$ and from 30 months to 42 months $(p=0.02)$.

Conclusions Sleep duration in children with ASD is reduced from 30 months of age and persists until adolescence.

\section{INTRODUCTION}

Autistic spectrum disorders (ASDs) are lifelong pervasive developmental disorders characterised by delayed and disordered communication skills, impaired social interaction and repetitive and restrictive patterns of behaviour. ${ }^{1}$ A wide range of comorbidities and concurrent disorders are recognised to be associated with $\mathrm{ASD},{ }^{2}$ including sleep disorders. ${ }^{3}$

Children with ASD are more likely to have disturbed sleep than typically developing children and those with other developmental disabilities: a recent report based on parental questionnaires suggested a 53\% prevalence of sleep disturbance in children with ASD aged 2-5 years old compared with $46 \%$ in children with developmental delay and $32 \%$ in typically developing children. ${ }^{4}$ The most commonly reported sleep disturbances are increased sleep latency and frequent night waking which result in reduced sleep duration. ${ }^{5} 6$ Other problems reported by parents include early morning waking, lack of sleep routine, nightmares and reduced sleep duration. ${ }^{8}$ The aetiology of

\section{What is already known on this topic}

- Children with autistic spectrum disorders (ASDs) are recognised to be more likely to have disturbed sleep than typically developing children.

- Most research studies of sleep in ASD are cross-sectional, and many are limited by small sample sizes and retrospective recall of sleeping patterns.

\section{What this study adds}

- Using prospectively collected data, total sleep duration in children with autistic spectrum disorders (ASDs) was reduced compared with peers from 30 months of age and persisted until adolescence.

- Children with ASD showed a reduction in night-time sleep, to a maximum of $43 \mathrm{~min}$ at 81 months, and more frequent waking at night.

- Changes in sleeping patterns in ASD were most pronounced between 18 months and 42 months of age. 


\section{METHODS}

\section{Sample}

The Avon Longitudinal Study of Parents and Children (ALSPAC) is a longitudinal cohort study following the health and development of children who had an expected date of delivery between April 1991 and December 1992, and were resident in the Avon area of south-west England at the time of their birth. ${ }^{13} \mathrm{~A}$ total of 14541 mothers were enrolled in pregnancy, resulting in a cohort of 14062 children. The Avon area had a population broadly typical of England in the 1991 census, with a mixture of rural and urban communities. Full details are available on the ALSPAC website: http://www.bristol.ac.uk/alspac. ${ }^{14}$ Ethical approval for the study was obtained from the ALSPAC Law and Ethics Committee and the Local Research Ethics Committees.

\section{Identification of cases of ASD}

The children within ALSPAC with a diagnosis of ASD by age 11 years were identified from two independent sources: (a) the clinical records of all children in the cohort investigated for a suspected developmental disorder by a multidisciplinary assessment (b) the national educational database in England (Pupil Level Annual Schools Census) which identified all children in state schools (over $90 \%$ of children) needing special educational provision in 2003. A total of 86 children were identified from both sources: 30 children with classical childhood autism, 15 with atypical autism and 23 with Asperger's syndrome: 18 of the ASD cases from the educational database could not be classified, as they were not subject to a multidisciplinary assessment. Median age at diagnosis ranged from 45 months in childhood autism to 116 months in Asperger's syndrome. Details of the methods used in the identification of ASD in the ALSPAC cohort have previously been reported. ${ }^{15}$

\section{Sleep data}

Parental questionnaires at 6 months, 18 months, 30 months, 42 months, 69 months, 81 months, 115 months and 140 months of age asked detailed questions about children's sleep patterns. A more detailed account of the sleep data methodology and analysis has recently been published. ${ }^{16}$ The questions included what time (to the nearest minute) the infant or child 'normally' went to bed in the evening and woke in the morning on an average weekday; from this response, night-time sleep duration was calculated, along with a categorical approximation of daytime sleep (none, $<1 \mathrm{~h}, 1-2 \mathrm{~h},>2 \mathrm{~h}$, from which estimates of $0,0.5,1.5$ and 2.5 , respectively, were used). Total daily sleep duration (unrounded) was derived from these data. Previous analysis $^{16}$ has shown reduced sleep duration across all time points for boys $(5-10 \mathrm{~min})$, for children of non-white ethnicity $(5-20 \mathrm{~min})$ and for children with three or more siblings (5-15 min).

Parents were asked about the number of times the infant or child woke during the night for the first seven time points (6-115 months, inclusive). Night-time waking events were categorised into none, 1, 2 or 3 or more. Frequent waking for this analysis was defined as an infant or child waking three or more times during the night-time sleep. The questionnaires used can be accessed on the ALSPAC website in a searchable database. ${ }^{17}$

\section{Social Communication Disorders Checklist}

The Social Communication Disorders Checklist $(\mathrm{SCDC})^{18}$ is a 12-item parental questionnaire that measures social skills and verbal/non-verbal characteristics typical of those found in ASD. This questionnaire has been evaluated as a screening tool for autism and found to predict autism with a sensitivity of 0.9 and specificity of $0.69 .{ }^{18}$ The SCDC was administered by parental questionnaire to the ALSPAC cohort at age 7 years, and scores resulted in a continuous variable, with boys having mean scores $30 \%$ higher than girls. ${ }^{19}$ As a secondary analysis, we investigated whether social communication difficulties (above the clinical cut-off of 9 on the SCDC) correlated with sleeping patterns.

\section{Cognitive and educational data}

The ALSPAC database includes an IQ measured at 7 years using a short version of the Weschler Intelligence Scale for Children 3rd edition (WISC-III), and data from Standardized Assessment Test results obtained from Local Education Authorities in England. These tests are compulsory for children in state funded schools in England, but are optional for independent private schools. Key Stage One (KS1) comprises years 1-2 at primary school (ages 5-7 years) and includes compulsory national tests at 7 years of age in reading, writing and mathematics. Educational attainment in Standardized Assessment Tests is categorised into National Curriculum Levels 1-8. At KS1, children are expected to achieve scores of level 2 or above. KS1 scores of 0 or level 1 were used to identify children with learning difficulties.

\section{Statistical analysis}

Data manipulation and analysis was performed using STATA V.11 and SPSS V.16. Sleep duration was normally distributed at all time points, and means and SDs were used to describe the (unrounded) data. Comparisons between continuous distributions were made using the $t$ test, whereas for categorical data, the $\chi^{2}$ test was used (for expected cells $<5$, the Fisher's exact test was used).

Sleep variables for ASD cases were compared with the rest of the cohort, using multivariable logistic regression modelling controlling for factors previously found to be significantly associated with ASD in the ALSPAC cohort. ${ }^{15}$ A forward stepwise regression model was implemented, and tests for interaction were used for analysis of KS1 educational data. The final model adjusted for sex, ethnicity, high parity (four or more children in a family) and comorbid epilepsy. A similar analysis was performed using children with a SCDC score of 9 or above (the clinical cut-off), to assess the correlation of altered sleep habits with social communication traits.

Centiles were constructed by using the mean and SD at each time point. Rates of falls in sleep duration in individuals with ASD and controls were then calculated by considering the proportion of children at each time point with a substantially decreased sleep duration (set at $1 \mathrm{SD}$ or more).

\section{RESULTS}

\section{Sample size and attrition}

Sleep duration data were available for a maximum of 73 ASD cases and 10704 controls at 18 months, but numbers, as expected, fell over time due to attrition from the cohort. By 140 months (11 years) sleep data were available on 39 children with ASD and from 7043 controls in the rest of the cohort. Children attending research clinics and those with returned questionnaires were more likely to come from families of higher socioeconomic class, with higher maternal educational level and secure housing tenure ( $\mathrm{p} \leq 0.01$ for all).

\section{Total sleep duration}

Prior to 30 months, no significant difference in sleep duration was found: from 30 months, children with ASD showed a trend towards reduced total sleep duration which continued 
Table 1 Mean total sleep duration and mean bedtimes and wake times for children with autistic spectrum disorders (ASDs) compared with the rest of the cohort

\begin{tabular}{|c|c|c|c|c|c|c|c|c|c|c|c|c|c|}
\hline \multirow[b]{3}{*}{ Age (months) } & \multicolumn{5}{|c|}{ Children with ASD } & \multicolumn{5}{|c|}{ Rest of the cohort } & \multicolumn{3}{|c|}{ Difference in duration } \\
\hline & \multirow[b]{2}{*}{$\mathbf{n}$} & \multicolumn{2}{|c|}{$\begin{array}{l}\text { Mean sleep } \\
\text { timings ( } 24 \mathrm{~h} \\
\text { clock) }\end{array}$} & \multicolumn{2}{|c|}{$\begin{array}{l}\text { Mean total sleep } \\
\text { duration }(\mathrm{m})\end{array}$} & \multirow[b]{2}{*}{$\mathbf{n}$} & \multicolumn{2}{|c|}{$\begin{array}{l}\text { Mean sleep } \\
\text { timings ( } 24 \mathrm{~h} \\
\text { clock) }\end{array}$} & \multicolumn{2}{|c|}{$\begin{array}{l}\text { Mean total sleep } \\
\text { duration }\end{array}$} & \multirow[b]{2}{*}{ Mean Diff (min) } & \multirow[b]{2}{*}{$\mathrm{Cl}$ of difference (min) } & \multirow[b]{2}{*}{ p Value* } \\
\hline & & Bed & Wake & Mean & SD & & Bed & Wake & Mean & SD & & & \\
\hline 6 & 67 & 20:05 & 7:02 & $13 \mathrm{~h} 24 \mathrm{~m}$ & $1 \mathrm{~h} 44 \mathrm{~m}$ & 11230 & $20: 08$ & $6: 56$ & $13 \mathrm{~h} 12 \mathrm{~m}$ & $1 \mathrm{~h} 43 \mathrm{~m}$ & +12 & $(-13$ to +37$)$ & 0.35 \\
\hline 8 & 73 & $19: 39$ & $7: 02$ & 12 h 51 m & $1 \mathrm{~h} 11 \mathrm{~m}$ & 10704 & $19: 46$ & 7:06 & 12 h $47 \mathrm{~m}$ & $1 \mathrm{~h} 13 \mathrm{~m}$ & $+4 \min$ & $(-13$ to +21$)$ & 0.62 \\
\hline 30 & 65 & $19: 52$ & $6: 42$ & $11 \mathrm{~h} 41 \mathrm{~m}$ & $1 \mathrm{~h} 05 \mathrm{~m}$ & 9555 & $19: 50$ & $7: 04$ & $11 \mathrm{~h} 58 \mathrm{~m}$ & $1 \mathrm{~h} 05 \mathrm{~m}$ & $-17 \min$ & $(-1$ to -33$)$ & 0.032 \\
\hline 42 & 63 & $20: 01$ & $6: 47$ & $11 \mathrm{~h} 03 \mathrm{~m}$ & $1 \mathrm{~h} 15 \mathrm{~m}$ & 9522 & $19: 46$ & $7: 02$ & $11 \mathrm{~h} 31 \mathrm{~m}$ & $0 \mathrm{~h} 56 \mathrm{~m}$ & $-28 \min$ & $(-14$ to -42$)$ & 0.001 \\
\hline 69 & 60 & $20: 11$ & $6: 57$ & $10 \mathrm{~h} 48 \mathrm{~m}$ & $1 \mathrm{~h} 04 \mathrm{~m}$ & 8490 & $19: 52$ & $7: 10$ & $11 \mathrm{~h} 18 \mathrm{~m}$ & $0 \mathrm{~h} 42 \mathrm{~m}$ & $-30 \min$ & $(-19$ to -41$)$ & $<0.0001$ \\
\hline 81 & 57 & $20: 28$ & $6: 54$ & $10 \mathrm{~h} 26 \mathrm{~m}$ & $0 \mathrm{~h} 56 \mathrm{~m}$ & 8208 & $20: 04$ & $7: 12$ & $11 \mathrm{~h} 09 \mathrm{~m}$ & $0 \mathrm{~h} 40 \mathrm{~m}$ & $-43 \min$ & $(-32$ to -53$)$ & $<0.0001$ \\
\hline 115 & 55 & $21: 02$ & 7:03 & $10 \mathrm{~h} 01 \mathrm{~m}$ & $1 \mathrm{~h} 04 \mathrm{~m}$ & 7761 & $20: 51$ & $7: 17$ & $10 \mathrm{~h} 27 \mathrm{~m}$ & $0 \mathrm{~h} 39 \mathrm{~m}$ & $-26 \min$ & $(-16$ to -37$)$ & $<0.0001$ \\
\hline 140 & 39 & $21: 28$ & $6: 57$ & 9 h 29 m & $0 \mathrm{~h} 56 \mathrm{~m}$ & 7043 & $21: 21$ & $7: 10$ & 9 h 49 m & $0 \mathrm{~h} 39 \mathrm{~m}$ & $-20 \min$ & $(-8$ to -32$)$ & 0.001 \\
\hline
\end{tabular}

${ }^{*}$ t test.

throughout childhood (table 1). The difference in total sleep duration remained significant at 140 months of age; the difference was greatest $(43 \mathrm{~min})$ at 81 months $(\mathrm{p}=<0.0001)$, reducing to $20 \mathrm{~min}$ at 140 months of age $(\mathrm{p}=0.001)$ (see figure 1$)$.

These differences in total sleep duration remained very similar in a multivariable linear regression model, adjusting for sex, ethnicity, high parity and epilepsy. Male gender was the most influential factor in the regression model. Prematurity, low birth weight, maternal education, paternal social class and sleepdisordered breathing were all tested at the univariable level but were not significantly associated with sleep duration in ASD.

Differences in total sleep duration were wholly due to a reduction in night-time sleep duration (see figure 2). Night-time sleep duration was influenced by differences in bedtime and wake time (presented in table 1). Daytime sleep duration was not significantly different between the two groups (see figure 3 ).

IQ scores were only available for 21 children with ASD in the cohort, so educational attainment (KS1 scores) were used as a proxy for learning disability. KS1 data were available for 62 of the children with ASD and over 11000 children in the rest of the cohort. Thirty-seven per cent of children with ASD had a score of 0 or 1 , compared with $3 \%$ of the rest of the cohort $(p=0.0001)$. However, no consistent difference was found in

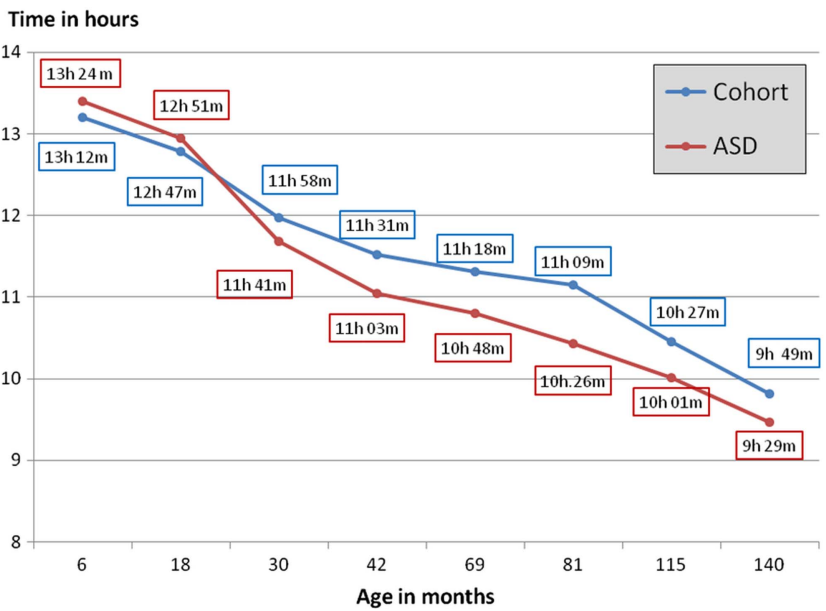

Figure 1 Total mean sleep duration in children with autistic spectrum disorders (ASDs) compared with the rest of the cohort. total sleep duration between ASD cases with and without learning disability.

Total sleep duration was analysed in children with high SCDC scores (>9), and compared with the rest of the cohort. The trend of reduced sleep duration in children with social communication difficulties was consistent with that found in the ASD cases, although was not as pronounced, and was statistically significant from 42 months to 140 months of age $(p<0.01)$.

\section{Night-time waking}

Children with ASD woke more frequently at night. Frequent waking (defined as three or more times a night) was statistically significant from 30 months of age, with $13 \%$ of children with ASD waking more than three times a night compared with $5 \%$ of the cohort (see table 2). This difference became more pronounced with age, $11 \%$ of children with ASD waking more than three times a night at 81 months compared with only $0.5 \%$ of the rest of the cohort.

Tracking changes in sleep duration across sleep centiles Comparing children who decreased sleep duration between two consecutive time points by more than $1 \mathrm{SD}$, there was a greater proportion of children with ASD at most intervals, although

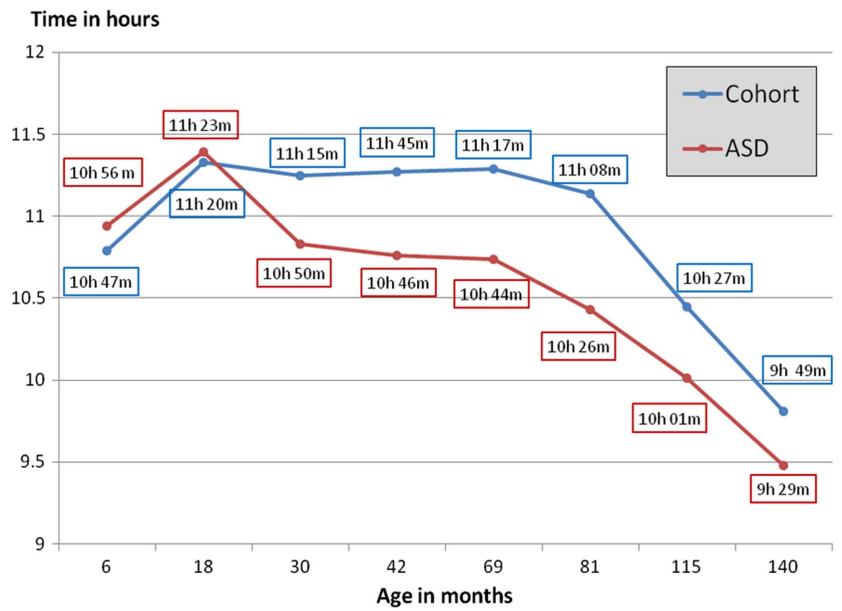

Figure 2 Night-time mean sleep duration in children with autistic spectrum disorders (ASDs) compared with the rest of the cohort. 


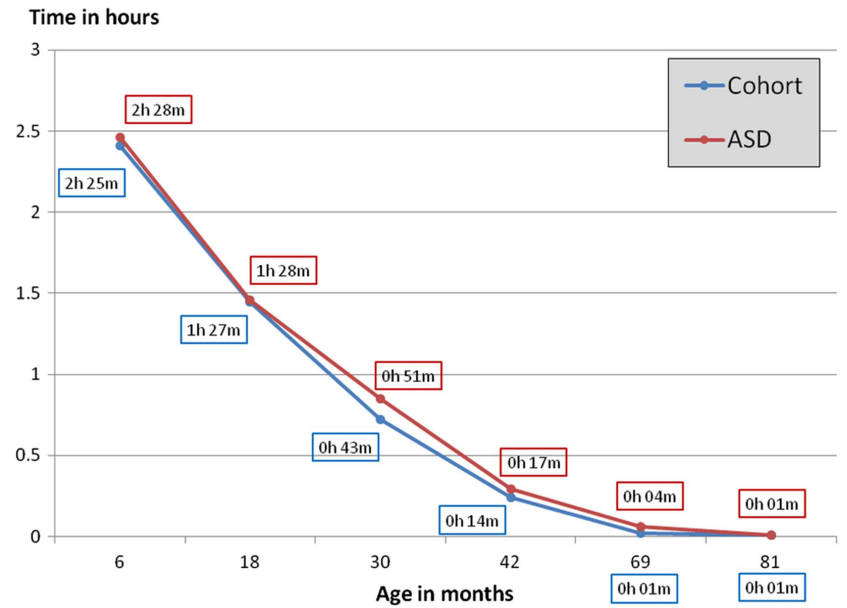

Figure 3 Daytime mean sleep duration in children with autistic spectrum disorders (ASDs) compared with the rest of the cohort.

this was only statistically significant at 30 months $(p=0.04)$ and 42 months $(p=0.004)$. From 18 months to 42 months nighttime sleep duration fell by a further hour in ASD cases compared with controls. These differences remained statistically significant when controlling for confounders $(p=0.045$ and 0.02 respectively).

\section{DISCUSSION}

This longitudinal prospective study demonstrated that children with ASD had reduced total sleep duration when compared with contemporary controls, from 30 months to early adolescence. The differences were primarily during night-time sleep, and the individual changes in sleep pattern were most pronounced between 18 months and 42 months.

The strength of this study is that it is the first longitudinal description of reduced sleep duration and night waking in children with ASD using prospectively collected data, reported by the parents before their child was diagnosed with an ASD. The main limitation is the missing data due to attrition, which was more marked among the children with ASD and among children from poorer backgrounds. The ASD prevalence at 11 years in ALSPAC was lower than previously reported in England, ${ }^{20}$ and it is probable that some higher functioning children on the autistic spectrum were not included as they had not been diagnosed by age 11 years.

Table 2 Frequent night-time waking for children with autistic spectrum disorders (ASD) compared with the rest of the cohort (three or more times during the night)

\begin{tabular}{|c|c|c|c|c|c|}
\hline \multirow{2}{*}{$\begin{array}{l}\text { Time point } \\
\text { (months) }\end{array}$} & \multicolumn{2}{|c|}{$\begin{array}{l}\text { Children with } \\
\text { ASD }\end{array}$} & \multicolumn{2}{|c|}{ Rest of the cohort } & \multirow[b]{2}{*}{ p Value } \\
\hline & $n / N$ & $\%$ & $n / N$ & $\%$ & \\
\hline 6 & $8 / 66$ & 12.1 & $1061 / 11147$ & 9.5 & 0.47 \\
\hline 18 & $6 / 72$ & 8.3 & $703 / 10485$ & 6.7 & $0.48^{*}$ \\
\hline 30 & $8 / 64$ & 12.5 & $473 / 9442$ & 5.0 & $0.02^{*}$ \\
\hline 42 & $6 / 62$ & 9.7 & $261 / 9449$ & 2.8 & $0.008^{*}$ \\
\hline 69 & $4 / 56$ & 7.1 & $63 / 8243$ & 0.8 & $0.001^{*}$ \\
\hline 81 & $5 / 55$ & 10.9 & $43 / 8033$ & 0.5 & $0.001^{*}$ \\
\hline 115 & $3 / 47$ & 6.4 & $35 / 7306$ & 0.5 & $0.002^{*}$ \\
\hline
\end{tabular}

A second limitation of this study is the estimation of sleep duration by parental report only, without actigraphy or polysomnography. Actigraphy would have been the only possible objective proxy measurement for sleep in such a large cohort, but has drawbacks such as it may interpret restless sleep as being awake. ${ }^{21}$ In children with ASD actigraphy is often poorly tolerated: Souders et $a l^{9}$ compared 59 children with ASD with 40 control subjects using a variety of subjective and objective sleep measures, including actigraphy, and found that the subjective and objective measures yielded very similar estimates of the rate of sleep disturbances in their ASD cohort.

Studies have generally demonstrated parental reports to be in keeping with or to be an underestimation of sleep disturbances in children, ${ }^{22}$ although some research has suggested that parents over-report sleep problems. ${ }^{23}$ Total sleep duration was derived from parental reports of estimated bedtime, wake-time and daytime naps. An estimated bedtime did not differentiate between when the child goes to bed and goes to sleep, and therefore did not account for sleep latency. Also night-time sleep duration did not take into account duration of waking events, reported to be frequent in the population with ASD. The narrowing of the reported difference between ASD and controls in duration of sleep as children get older may be because older children with ASD learn to stay in bed when they wake, and are less demanding of parental attention at night.

The large variation in sleep duration in children in the ALSPAC cohort, ${ }^{16}$ also reported in US children and adolescents, ${ }^{24}$ suggests that the difference in total sleep seen in ASD may be of modest clinical importance, as it lies within the wide normal CIs. Although disturbed sleep is linked to poor daytime behaviour and family distress, ${ }^{23}$ we can only speculate whether the size of this reduction in sleep duration in children with ASD had an impact on development, intellectual functioning and autistic behaviours.

In experimental models sleep loss has an impact on daytime learning and behaviour, although the size of this impact is unclear and inconsistent. ${ }^{25}$ At a neurobiological level, some researchers speculate that sleep loss may cause actual neuronal loss. $^{26}$ If this hypothesis of cumulative sleep reduction resulting in neuronal loss is confirmed, then clinically the ASD population might gain from even a small consistent increase in total sleep time.

Sleep duration in childhood decreases over time. ${ }^{16}{ }^{24}$ When we took this into account by normalising the distribution at each time point we showed marked differences between the children with ASD and the rest of the cohort between ages 18 months and 42 months. Using ALSPAC, we reported a similar but later pattern in the development of sleep patterns in attention deficit hyperactivity disorder, with the biggest difference in sleep duration between attention deficit hyperactivity disorder and controls seen from 42 months to 69 months. ${ }^{27}$

Although we could not show any difference between children with ASD with and without learning difficulties, disturbed sleep patterns in ASD do appear to be different from those seen in children with intellectual disabilities. ${ }^{28} 29$ We speculate that such widespread and early effects on sleep duration reflect an underlying shared neuropathological basis between autism and disturbances of the biological clock. ${ }^{29} 30$ There are increasing biochemical and genetic data to support the existence of fundamental disturbances in circadian melatonin production in some children with autism, which may partly explain these findings. Children with ASD are reported to have reduced levels of circulating melatonin and disrupted circadian rhythms, and links have been identified between genes involved in melatonin synthesis 
and ASD, ${ }^{31}$ which could help explain the disturbed sleep patterns observed in children with ASD. An increasing body of evidence from trials ${ }^{32}$ demonstrates that oral melatonin can reduce sleep latency ${ }^{1132}$ and increase sleep duration ${ }^{33}$ in ASD.

In conclusion, this research emphasises the importance of assessing sleep disturbances early in children with ASD, to offer support and anticipatory guidance to parents and to consider the use of melatonin to reduce sleep latency.

Acknowledgements We are extremely grateful to all the families who took part in this study, the midwives for their help in recruiting them and the whole ALSPAC team, which includes interviewers, computer and laboratory technicians, clerical workers, research scientists, volunteers, managers, receptionists and nurses. The UK Medical Research Council (Grant ref: 74882) the Wellcome Trust (Grant ref: 076467) and the University of Bristol provide core support for ALSPAC.

Contributors JSH undertook the analyses under supervision, interpreted the findings, contributed to earlier versions of the paper and approved the final version of the manuscript for publication. PG obtained the funding for the analysis, contributed to study design and data interpretation, edited early drafts and approved the final version of the manuscript for publication. PSB undertook most of the analyses of sleep data in ALSPAC and supervised JSH on this project. He contributed to data interpretation and approved the final version of the manuscript for publication. NS contributed to study design and data interpretation and approved the final version of the manuscript for publication. JH contributed to study design and data interpretation, edited early drafts and approved the final version of the manuscript for publication. PJF designed the ALSPAC sleep questions, contributed to study design and data interpretation and approved the final version of the manuscript for publication. AME identified autistic spectrum disorders in ALSPAC, oversaw study design and data interpretation, wrote the first draft of the paper and approved the final version of the manuscript for publication.

Funding Guy's and St Thomas' Charity (Grant ref: S091017) helped support PSB to undertake specific statistical analysis on ALSPAC sleep data.

Competing interests None.

Ethics approval ALSPAC Law and Ethics Committee and the Bristol Local Research Ethics Committees.

Provenance and peer review Not commissioned; externally peer reviewed.

Data sharing statement ALSPAC has well-developed methods to support the sharing of data, and strict policies to ensure confidentiality of participants. Details on ALSPAC's data sharing policy can been found at www.bristol.ac.uk/alspac/ sci-com/collab-policyl.

Open Access This is an Open Access article distributed in accordance with the Creative Commons Attribution Non Commercial (CC BY-NC 3.0) license, which permits others to distribute, remix, adapt, build upon this work non-commercially, and license their derivative works on different terms, provided the original work is properly cited and the use is non-commercial. See: http://creativecommons.org/licenses/by-nc/3.0/

\section{REFERENCES}

1 American Psychiatric Association. Diagnostic and statistical manual of menta disorders: DSM-IV-TR. Washington, DC: American Psychiatric Association, 2000.

2 Hughes J. Update on autism: a review of 1300 reports published in 2008. Epilepsy Behav 2009;16:569-89.

3 Johnson KP, Giannotti F, Cortesi F. Sleep patterns in autism spectrum disorders. Child Adolesc Psychiatr Clin N Am 2009;18:917-28.

4 Krakowiak P, Goodlin-Jones B, Hertz-Picciotto I, et al. Sleep problems in children with autism spectrum disorders, developmental delays, and typical development: a population-based study. I Sleep Res 2008;17:197-206.

5 Giannotti F, Cortesi F, Cerquiglini A, et al. Sleep in children with autism with and without autistic regression. J Sleep Res. 2011;20:338-47.

6 Richdale A, Schreck K. Sleep problems in autism spectrum disorders: prevalence, nature, and possible biopsychosocial aetiologies. Sleep Med Rev 2009;13:403-11.
7 Honomichl RD, Goodlin-Jones BL, Burnham M, et al. Sleep patterns of children with pervasive developmental disorders. J Autism Dev Disord 2002;32:553-61.

8 Goldman SE, Surdyka K, Cuevas R, et al. Defining the sleep phenotype in children with autism. Dev Neuropsychol 2009;34:560-73.

9 Souders MC, Mason TBA, Valladares 0 , et al. Sleep behaviors and sleep quality in children with autism spectrum disorders. Sleep 2009;32:1566-78.

10 Schreck KA, Mulick JA, Smith AF. Sleep problems as possible predictors of intensified symptoms of autism. Res Dev Disabil 2004;25:57-66.

11 Gringras P, Gamble C, Jones AP, et al., on behalf of the MENDS Study Group. Melatonin for sleep problems in children with neurodevelopmental disorders: randomised double masked placebo controlled trial. BMJ 2012;345:e6664.

12 Owens J, Spirito A, McGuinn M. The Children's Sleep Habits Questionnaire (CSHQ): psychometric properties of a survey instrument for school-aged children. Sleep 2000:23:1043-51.

13 Boyd A, Golding J, Macleod J, et al. Cohort Profile: The 'Children of the 90s'-the index offspring of the Avon Longitudinal Study of Parents and Children. Int J Epidemiol 2013;42:111-27.

14 Avon Longitudinal Study of Parents and Children (ALSPAC) http://www.bristol.ac.uk/ alspac

15 Williams E, Thomas K, Sidebotham H, et al. Prevalence and characteristics of autistic spectrum disorders in the ALSPAC cohort. Dev Med Child Neuro 2008;50:672-7.

16 Blair PS, Humphreys JS, Gringras P, et al. Childhood sleep duration and associated demographic characteristics in an English cohort. Sleep 2012;35:353-60.

17 ALSPAC questionnaires: http://www.bristol.ac.uk/alspac/researchers/data-access/ data-dictionary/

18 Berument SK, Rutter M, Lord C, et al. Autism screening questionnaire: diagnostic validity. Br J Psychiatry 1999;175:444-51.

19 Skuse DH, Mandy W, Steer C, et al. Social communication competence and functional adaptation in a general population of children: preliminary evidence for sex-by-verbal IQ differential risk. J Am Acad Child Adolesc Psychiatry 2009:48:128-37.

20 Baird G, Simonoff E, Pickles A, et al. Prevalence of disorders of the autism spectrum in a population cohort of children in South Thames: the Special Needs and Autism Project (SNAP). Lancet 2006;368:210-15.

21 Sadeh A. The role and validity of actigraphy in sleep medicine: An update. Sleep Med Rev 2011;15:259-67.

22 Reed HE, McGrew SG, Artibee K, et al. Parent-based sleep education workshops in autism. J Child Neurol 2009;8:936-45.

23 Wiggs L, Stores G. Sleep patterns and sleep disorders in children with autistic spectrum disorders: insights using parent report and actigraphy. Dev Med Child Neurol 2004;46:372-80

24 Williams JA, Zimmerman FJ, Bell JF. Norms and trends of sleep time among US Children and Adolescents JAMA Pediatr 2013;167:55-60.

25 Hill CM, Hogan AM, Karmiloff-Smith A. To sleep, perchance to enrich learning? Arch Dis Child 2007;92:637-43.

26 Jan JE, Reiter RJ, Bax MCO, et al. Long-term sleep disturbance in children: a cause of neuronal loss. Eur J Neurol 2010;14:380-90.

27 Scott N, Blair P, Emond A, et al. Sleep patterns in children with ADHD: a population-based cohort study from birth to 11 years. I Sleep Res 2012;22: 121-8.

28 Bruni $\mathrm{O}$, Ferri $\mathrm{R}$, Vittori $\mathrm{E}$, et al. Sleep architecture and NREM alterations in children and adolescents with Asperger syndrome. Sleep 2007;30:1577-85.

29 Elia M, Ferri R, Musumeci SA, et al. Sleep in subjects with autistic disorder: a neurophysiological and psychological study. Brain Dev 2000;22:88-92.

30 Bourgeron T. The possible interplay of synaptic and clock genes in autism spectrum disorders. Cold Spring Harb Symp Quant Biol 2007;72:645-54.

31 Rossignol DA, Frye RE. Melatonin in autism spectrum disorders: a systematic review and meta-analysis. Dev Med Child Neurol 2011;53:783-92.

32 Malow B, Adkins KW, McGrew SG, et al. Melatonin for sleep in children with Autism: a controlled trial examining dose, tolerability, and outcomes. I Autism Dev Disord 2012;42:1729-37.

33 Cortesi F, Giannotti F, Sebastiani T, et al. Controlled-release melatonin, singly and combined with cognitive behavioural therapy, for persistent insomnia in children with autism spectrum disorders: a randomized placebo-controlled trial. J Sleep Res $2012 ; 21: 700-9$ 